\title{
La Preposición $D E$ Como Inicio de Locución: Sus PATRONES Y SU FRECUENCIA DE Uso
}

\author{
The preposition 'de' in phrase-initial position: forms \\ and frequency
}

Juan Martinez Lopez *
Annette Jørgensen**

\section{INTRODUCCIÓN}

No son escasos los estudios dedicados a profundizar en el conocimiento de la categoría del adverbio durante la última década. Estas investigaciones se han centrado tanto sobre el estudio de un tipo particular de adverbios, como sobre una forma adverbial muy concreta; en especial, en aquéllas que presentan, por diferentes causas, aspectos polifuncionales, o bien, una semántica y/o forma muy particular. En este contexto moderno, los estudios gramaticales que han tomado como base el adverbio desde su vertiente formal se han visto en la necesidad de redefinir la categoría, o, al menos, incorporar a su estudio ciertas unidades pluriverbales, nos referimos a las expresiones fijas o unidades fraseológicas que, en el discurso funcionan de forma autónoma en virtud de su fijación estructural: de buenas a primeras, de padre y muy señor mío, de buten, de película, etc. Como se sabe, tradicionalmente dichas unidades pluriverbales han quedado fuera del estudio gramatical debido a la ya superada tesis, según la cual la idea de categoría descansa sobre la noción de palabra, y ésta en la unidad de escritura. Paulatina y lentamente se fue reparando en que prácticamente todas las categorías heredadas excluían elementos que, a veces sin razonamiento aparente, o bien debido a causas diacrónicas, habían quedado concebidos mediante dos o más palabras, pero que semánticamente y funcionalmente en nada se diferenciaban del grupo de elementos

\footnotetext{
* Universidad Noruega de Ciencias Económicas y Empresariales (NHH)

** Universidad de Bergen
} 
LOPEZ, J. M.; JøRGENSEN, A. La Preposición DE Como Inicio de Locución...

monoverbales que formaba su categoría. Cabría añadir, además, que los elementos que forman dichas estructuras complejas se hallan completamente fijados, tal y como lo hacen las sílabas de una palabra. Más aún, en el caso que nos ocupa -los adverbios pluriverbales iniciados con la preposición de, los sufijos de los elementos que los forman han dejado de ser operativos genérica y numéricamente y, en virtud de su significado unitario, entran sin ningún tipo de reserva en la definición de adverbio: "parte invariable de la oración que modifica a un verbo, a un adjetivo o a otro adverbio"1.

Por otra parte, uno de los aspectos que pueden caracterizar los estudios lingüísticos desarrollados en la última década es el interés en profundizar en los mecanismos que explican el comportamiento del lenguaje oral. A este respecto se han intensificado, a raíz de los nuevos enfoques lingüísticos, tanto los estudios de carácter descriptivo como aquellos de orden más pragmático, dedicados a explicitar la función de determinados recursos propios del discurso oral, que -como es bien sabido- habían quedado fuera de los cauces de los estudios filológicos. Por ello, no es fruto de la casualidad el que durante los últimos años se hayan intensificado de modo espectacular los estudios sobre las expresiones fijas ${ }^{2}$ en sus más variadas manifestaciones. Ya muy recientemente se han llevado a cabo investigaciones con el fin de intentar sistematizar las manifestaciones léxicas pertenecientes al aspecto más fijo de las lenguas; no obstante, persisten ciertos aspectos de difícil análisis y no bien fundamentados científicamente.

El objetivo que aquí nos proponemos es profundizar en la estructura morfosintáctica de las locuciones adverbiales. Para ello analizaremos un corpus de 147 locuciones adverbiales cuyo denominador común es el empezar con la preposición de: de buten, de aquí te espero, de boquilla, de bruces, de carretilla, de cine, de cojones, etc. Dicho corpus supone la totalidad de este tipo de expresiones en dos diccionarios: uno que versa sobre la lengua general, como es el Diccionario de lengua española y otro de carácter fraseológico, el Diccionario de locuciones y expresiones familiares. Una vez recabadas todas las estructuras procederemos a establecer patrones funcionales, lo que nos permitirá observar qué estructuras son las más productivas y, por tanto, base para nuevas creaciones, y cuáles representan patrones poco eficaces para su reproducción en el proceso de creación de nuevas unidades.

BELLO, A. Gramática de la lengua castellana destinada al uso de los americanos. Cabildo Insular de Tenerife, Tenerife, 1981, p. 159.

Se emplea aquí el término expresión fija (al igual que se hará con unidad fraseológica, locución o fraseologismo), en sentido amplio, tal y como lo recogen por regla general los diccionarios, para referirnos a toda una serie de estructuras dispares cuyo denominador común es la frecuente coaparición de sus miembros en el decurso sintáctico. 
LopeZ, J. M.; JøRGEnSEN, A. LA Preposición DE Como Inicio de Locución...

Para comenzar desgranaremos las estructuras sintácticas de dicho corpus locucional, a fin de encontrar unos patrones sintácticos mínimos a los que puedan responder todas ellas. Posteriormente contrastaremos la totalidad de nuestras locuciones con el material existente en la base de datos www.corpusdelespanol.org. Dicha base de datos está constituida, en lo que respecta al siglo XX, por un corpus de aproximadamente veinte millones de palabras, distribuidas a partes iguales en tres tipos de texto: textos orales, textos literarios y otros escritos no literarios (fundamentalmente periodísticos y de divulgación) recogidos de la totalidad del mundo hispánico.

Ello nos permitirá ver qué patrones son los que presentan una mayor productividad en el campo de estas particulares locuciones adverbiales. De modo paralelo observaremos la frecuencia de uso de cada expresión fija en el corpus citado, y el porcentaje que cada una supone en la totalidad del corpus. Dicho análisis nos permitirá afirmar con cierta solvencia qué patrones son los más productivos y en qué medida un determinado patrón mantiene un equilibrio entre su productividad a la hora de crear nuevas unidades y el índice de frecuencia de las propias unidades en un corpus real y representativo.

No obstante, antes de entrar de lleno en el núcleo de este trabajo parece conveniente comentar grosso modo lo que hasta ahora se ha dicho de las locuciones y, en particular, de las denominadas locuciones adverbiales.

\section{LAS LOCUCIONES EN LA MODERNA LiNGÜísTICA HISPÁNICA}

Fue J. Casares (1992 [1950], p. 170) quien introdujo el término locución en el ámbito de la terminología lingüística, al que definió como: "Combinación estable de dos o más términos, que funcionan como elemento oracional y cuyo sentido unitario consabido no se justifica, sin más, como una suma del significado normal de los componentes". En su análisis para diseccionar los diferentes tipos de locuciones establece dos grandes grupos: por un lado, las locuciones "conceptuales o significantes" (aquellas a las que corresponde una representación mental, una idea o un concepto, aunque no sea el mismo que tiene fuera de las locuciones citadas); por otro, las locuciones "conexivas", esto es, aquellas en que "su humilde oficio se reduce a establecer un nexo sintáctico".

Las denominadas locuciones "conceptuales", las divide, a su vez, en "nominales" (de índole sustantiva o equivalente), "adjetivas" (las que hacen oficio de adjetivo, de brocha gorda), "verbales" (las que se componen de un verbo que, asimilando su complemento directo o preposicional, forman un predicado complejo, tomar el olivo), "participiales" (las que llevan un 
LOPEZ, J. M.; JøRGENSEN, A. LA Preposición DE Como Inicio de Locución...

participio en su estructura, hecho un brazo de mar), "adverbiales" (las que desempeñan la función de adverbio, por lo que pueden ser subdivididas en las mismas clases que estos, en un santiamén), "pronominales" (hacen el oficio de pronombre, cada quisque) y las "interjectivas o exclamativas" (votos, reniegos o juramentos y, en general, las exclamaciones en que entran varias palabras, ancha es Castilla!).

B. Pottier (1977 [1974], p. 324) define la "lexía" como "la unidad lexical memorizada", por lo que puede pertenecer a una categoría (forma del significado) o a clases superiores. Distingue cuatro tipos de lexías: a) Lexías simples, es decir las palabras: silla, coche; b) Lexías compuestas, como resultado de una integración semántica que se manifiesta formalmente: saca-corchos, pisa-papeles; c) Lexías complejas en las que una secuencia se halla en vías de lexicalización en mayor o menor grado: guerra fría, luz roja; y d) Lexías textuales: aquellas lexías complejas que alcanzan el nivel de un enunciado, es decir, refranes, adivinanzas, proverbios, etc. Las llamadas locuciones, en el trabajo de Pottier, quedarían en el tercer grupo señalado.

Posteriormente señala las propiedades de las lexías y los test para determinar si estamos ante una lexía. Con respecto a lo primero establece dos grupos: a) Las lexías estereotipadas, que son las que forman una secuencia memorizada invariable: no reparar en medios, con las manos en la masa, a vuelo de pájaro, así como otras en vías de lexicalización se sabe de fuentes generalmente bien informadas; b) Las lexías variables, que se componen de un marco estable y de una zona inestable: el primer/recién/ último nacido. Con respecto a los test de determinación de las lexías señala cuatro, indicando que ninguno en sí es suficiente, pero que cada uno revela ciertas propiedades: a) No-autonomía de algún componente: desternillarse de risa; b) No-conmutabilidad de algún componente: corriente y moliente; c) No-separabilidad de los componentes: es una mesa redonda (de conferencia) - *esa mesa es redonda; d) Particularidad de estructura interna, integración: perder ánimos, hacer justicia.

Pottier observa, sin entrar en los procesos de categorización, algunos elementos sobre los que descansa la fijación estructural de las expresiones fijas, hecho sobre el que poco después, como veremos, profundizó Zuluaga.

Más tarde, E. Coseriu desarrolla lo que él denomina "discurso repetido": aquello que "abarca todo lo que tradicionalmente está fijado como "expresión", "giro", "modismo", "frase" o "locución" y cuyos elementos constitutivos no son reemplazables o re-combinables según las reglas actuales de la lengua" (COSERIU, 1986, p. 113). Para este autor, "solo las 
manifestaciones basadas en la técnica libre del discurso ${ }^{3}$ son analizables sincrónicamente y, por esta razón, solo la técnica es "estructurable". Los elementos de las expresiones fijas no lo son, porque no son "conmutables". En efecto, las expresiones fijas no pueden ser analizadas en el sentido propio del término, ya que no se oponen libremente a otras expresiones por una parte cualquiera de sus elementos constitutivos: ellas significan -funcionan, por así decir, "en bloque"” (COSERIU, 1986, p. 114). Distingue tres subgrupos de expresiones fijas en función de la unidad a la que equivalen en el texto, esto es, si funcionan como una oración, sintagma, palabra:

a) El primer grupo esta fuertemente relacionado con la literatura tradicional de la comunidad donde se desarrolla y lo componen los proverbios, refranes, frases metafóricas, sentencias, adagios, etc. Para Coseriu se trata de unidades que solo son conmutables en el plano de las oraciones y de los textos, que constituyen documentos literarios en sentido amplio englobados en la tradición lingüística. Observa claramente que dichas unidades no tienen nada de "léxico", y propone para ellas el término "locuciones".

b) El segundo grupo estaría formado por las unidades que responden funcionalmente a sintagmas: atar cabos, hacerse el sueco, no dejar títere con cabeza, etc. Dado que se trata de combinaciones de palabras, el autor establece su equivalencia a combinaciones de la técnica libre del discurso, por lo que deberían estudiarse a nivel sintagmático. Señala que tampoco deberían ser estudiadas en la lexicografía y acuña el término "sintagmas estereotipados" para referirse a dichas unidades.

c) El tercer grupo lo formarían las llamadas perífrasis léxicas; en un santiamén, de cabo a rabo, etc. Dichas unidades, según el citado autor, equivalen a unidades lexemáticas (palabras) de la técnica libre del discurso.

\footnotetext{
Para este autor, la técnica libre del discurso "abarca las unidades léxicas y gramaticales (lexemas, categoremas, morfemas) y las reglas para su modificación y combinación en la oración, es decir, las palabras y los instrumentos y procedimientos léxicos y gramaticales" (COSERIU, 1986, p. 113).
} 
LOPEZ, J. M.; JøRGENSEN, A. LA Preposición DE CoMo INICIO de Locución...

Para nuestro estudio, son los dos últimos grupos los que tienen mayor interés. Con respecto al grupo (c), el autor afirma que está formado por unidades del discurso repetido que, pese a funcionar en el interior de la oración, son conmutables por palabras. Por esta razón, cree que dicho grupo ha de ser acogido en las obras lexicográficas. Pese a la creación teórica, el mismo Coseriu (1986: 118) admite que es difícil establecer una línea divisoria clara entre los grupos (b) y (c), dado que la conmutación no es un factor determinante, pues hay sintagmas que pueden sustituir a palabras y viceversa.

Partiendo de diversos criterios, Zuluaga (1980) elabora varias clasificaciones. El resultado es una estructuración de las unidades fraseológicas (UF) en tres tipos:

1. - Tomando la semántica como punto de partida, agrupa las UF en cuatro subtipos:

a) UF de sentido literal, es decir, meramente fijas: común $y$ corriente.

b) UF mixtas, esto es, con una parte literal y otra de sentido figurado: por si las moscas = por si acaso $;$ a mí plin = a mí no me importa.

c) UF semiidiomáticas: más papista que el Papa.

d) UF idiomáticas: tirios y troyanos, dormirse en los laureles.

2. - Según el tipo de fijación, se agrupan en cinco subtipos:

a) UF con fijación de categorías gramaticales: pagar los platos rotos, cortar el bacalao.

b) UF con fijación del orden de sus componentes: tirios y troyanos, a capa y espada, con uñas y dientes.

c) UF con fijación pragmática: buenas noches, muchas gracias.

d) UF con fijación de anomalías estructurales: a pies juntillas.

e) UF con componentes únicos: a la topa tolondro.

3. - Según su funcionalidad en el discurso, es decir, ya sean textos, oraciones gramaticales, sintagmas, unidades léxicas o unidades gramaticales, se dividen en tres grandes grupos:

a) UF que constituyen por sí mismas enunciados completos; en otras palabras, no dependen de un contexto verbal inmediato para constituir una expresión de sentido completo. A estas las llama enunciados fraseológicos: estábamos pocos y parió abuela. 
b) UF que requieren contexto verbal inmediato. Son las que se combinan con otros elementos en el interior de la frase. Se trata, por tanto, de las locuciones señaladas por Casares: de higos a brevas, dar gato por liebre.

c) UF que presentan la autonomía semántico-sintáctica propia de la frase, pero que en su funcionalidad real no llegan a constituir enunciados con valor de texto. A éstas las denomina frasescliché: qué se yo.

Como se puede observar, Zuluaga (1980) no sólo analiza la estructura interna de los fraseologismos, sino que estudia su valor funcional, esto es, la función sintáctica que en el discurso desempeñan las expresiones fijas. En este contexto y al margen de lo señalado, delimita dos grandes grupos: los que por sí mismos forman enunciados (enunciados fraseológicos), y los que necesitan de otros elementos con los que combinarse para aparecer en el discurso (locuciones).

Un nuevo intento de estructuración de los fraseologismos es el llevado a cabo por Tristá Pérez (1980, p. 29), quien los agrupa partiendo del análisis de su estructura interna, a la vez que establece dos grandes grupos:

1. - Aquellas unidades pluriverbales que portan un elemento identificador, que puede ser de carácter léxico, semántico o gramatical.

2. - Aquellas unidades en cuya estructura no se observa ningún tipo de anomalía (léxica, semántica ${ }^{4}$ o gramatical) que pueda marcar diferencias entre una y otra combinación.

Si trasladamos las particularidades que Tristá Pérez (1980) señala al campo de las locuciones adverbiales, podemos encontrar con facilidad ejemplos de los diferentes subgrupos a que alude la autora: así, en el caso de las locuciones que nos ocupan, podríamos señalar, en relación con el primer grupo, expresiones con anomalías léxicas por contar en su estructura con elementos onomatopéyicos: al tuntún, en el año catapún, o bien con palabras que carecen de sentido propio fuera de la expresión fija (son las

No nos parece el mejor parámetro recurrir a las diferencias basadas en la proyección metáfórica. De cualquier forma, la autora establece dos grupos de fraseologismos: aquéllos cuyo significado aparente no mantiene relación con los significados de los elementos formantes de la expresión (o al menos no es usual ver dichos elementos formando una combinación libre); y aquéllos en los que el sentido recto de la combinación libre determina el significado de la expresión fija. 
LOPEZ, J. M.; JøRGENSEN, A. La Preposición DE Como Inicio de Locución...

comúnmente denominadas palabras idiomáticas): de aupa, de balde, en vilo, en un tris, a la remanguillé, o con disfunciones sintácticas: a pies juntillas (falta de la obligada concordancia) o, por último, vocablos que se han insertado en el lenguaje general en el marco de una expresión fija, pero que proceden de algún lenguaje especializado, ya sea la música, el toreo, la religión, etc., o de otra lengua natural. Casos de este tipo son: al albur (con origen en un juego de naipes), al ralentí (del lenguaje de la automoción), a todo full (procedente del inglés).

En lo que respecta a fraseologismos que presentan anomalías semánticas, estos se hacen más evidentes en tanto que no admiten una interpretación literal: a cojón sentado.

La última propuesta de clasificación de las expresiones fijas a la que nos vamos a referir es la de Corpas (1996, p. 99 et seq.), quien establece tres grupos: las colocaciones, las locuciones y los enunciados fraseológicos. La definición de locución que Corpas propone no dista mucho de la adelantada por Casares (1992), cuya definición ha quedado, en líneas generales, bien asentada en la lingüística moderna. ${ }^{5}$ Corpas (1996) establece una diferenciación entre las combinaciones libres y las locuciones a partir de tres planos: el de la institucionalización, el de la estabilidad sintácticosemántica y el de la función denominativa.

En su estudio, Corpas (1996) destaca la abundancia de locuciones adverbiales, así como la complejidad sintáctica de estas expresiones: de punta a cabo, de la noche a la mañana, en vilo, con pelos y señales, por lo pronto, a la chita callando, con el corazón en la mano, etc. La autora observa que dichas locuciones pueden ser portadoras de distintos valores referenciales en el nivel semántico, si bien predominan los de modo: de ensueño, de extranjis, de coña, en condiciones, en debida forma, a escondidas, a carta cabal, a degüello. De cualquier forma, no son tampoco raras las locuciones que hacen referencia a una localización en el tiempo: de tarde en tarde, de mañana, de higos a brevas, a deshoras, etc., o en el

\footnotetext{
El Diccionario de Uso del Español (1992) define locución como: "Expresión pluriverbal de forma fija que se inserta en el habla como una pieza única, constituida por una oración simple o compuesta o una parte de oración". De modo similar lo hace el Diccionario de la Real Academia (1992) en su tercera acepción: “combinación estable de dos o más palabras, que funciona como oración o como elemento oracional, y cuyo sentido unitario no siempre se justifica, como suma del significado normal de los componentes". No obstante, este último diccionario no incluye explícitamente la locución nominal en la nómina de los tipos de locución. Pese a todo, estudios fraseológicos de relevancia realizados con posterioridad como es el Diccionario Fraseológico Documentado del Español Actual (2004) sí mantienen vigente el término "locución nominal": "Este DICCIONARIO no es un diccionario de palabras, sino de locuciones: agrupaciones más o menos fijas de palabras; conjuntos que tienen su función gramatical (nombre, pronombre, adjetivo, verbo, adverbio, preposición, etc.) como la tienen las palabras individuales; y que también, como si fuesen palabras individuales, tienen un valor estable propio" (p. XII).
} 
LopeZ, J. M.; JøRGEnSEN, A. LA Preposición DE Como Inicio de Locución...

espacio: al lado, a la vuelta de la esquina, en el quinto pino, en mis narices. Casares (1992 [1950]) observa también que con cierta frecuencia se hallan locuciones polifuncionales, es decir, aquellas que pueden funcionar tanto como complementos circunstanciales (su labor más general), como modificadores de un sustantivo:

1) Hemos visto una película de fábula

2) Su hijo come de fábula

\section{Las Locuciones Con La Preposición $D E$}

Como se observa, todo signo de este tipo se compone de un elemento pleno (sustantivo, adjetivo o adverbial) que establece el contenido léxico, y de algunos modificadores en ciertos casos (determinantes y/o adyacentes) que contribuyen en el momento de su formación a consolidar el significado adverbial de conjunto, además de la preposición de.

3.1. Para complementar este estudio nos referiremos brevemente a los valores de la preposición de, especialmente los vinculados a las peculiaridades que ésta mantiene en relación con el factor noción, muy diferentes de sus valores espaciales y temporales ${ }^{6}$. Pese a que la amplitud y borrosidad del espectro semántico de lo nocional en la preposición de es bastante opaco, siguiendo a M. L. López (1982) consideraremos que todos los sentidos que no están dentro de las coordenadas espacio-temporales pertenecen al valor "noción". Dicho valor lo ostenta en virtud de su unitaria estructura morfológica con los demás elementos que constituyen el adverbio.

Como es sabido, la preposición de sirve de elemento de enlace entre diferentes categorías, lo que permite establecer diferentes tipos de adyacencia: la adjetiva (cuando el núcleo lo conforma un sustantivo), y la adverbial (cuando el elemento nuclear es un verbo). Dado que nuestro corpus de trabajo lo forman adverbios pluriverbales, dejaremos al margen aquellas formas de adyacencia pluriverbal que enlaza con un sustantivo, y nos concentraremos en los casos en que dichas formaciones funcionan como adyacentes verbales.

\footnotetext{
LÓPEZ, María L. Problemas y métodos en el análisis de las preposiciones. Madrid: Gredos ${ }_{2} 1972$, p. 129 , partiendo de ideas de Portier y Brøndal, afirma que: "Cada preposición no tiene, en principio, en lengua más que una significación. Esta significación está formada por la reunión de un número de rasgos pertinentes que forman una imagen susceptible de ser dibujada grosso modo. De tal manera que la significación en lengua de una preposición equivale a su representación. En el discurso es donde las preposiciones adquieren matices nacidos del contexto".
} 
LOPEZ, J. M.; JøRGENSEN, A. LA PREPosición DE Como Inicio de Locución...

A diferencia de lo que ocurre con la adyacencia nominal, el valor nocional de la preposición de cómo encabezamiento de adverbio pluriverbal encuentra fuertes restricciones. De hecho, si nos atenemos a las reglas de la técnica libre del discurso (en oposición al discurso repetido y su generalizad proyección metafórica) no es difícil observar que de no puede encabezar complementos verbales más allá del denominado complemento preposicional o suplemento. Así, al margen de valores espaciales o temporales (el tren salió de Madrid, el congreso se desarrollará de martes a viernes) y valores locucionales (con sentido unitario) de gañote, de la cabeza a los pies, de pronto, de puta madre, la preposición de puede encabezar complementos preposicionales del tipo hablan de fútbol, vive de sus padres. Sin embargo, en estos casos es discutible el valor nocional de la preposición, al menos desde la tesis que defiende el valor intrínseco de ésta, ya que más bien parece que actúa sobre el sentido del núcleo verbal, esto es, que afectan a la semántica interna del verbo. Esta diferente forma de actuar sobre el verbo sea quizás la que permite que sólo en algunos casos sea viable sustituir esa preposición por otra (hablan de fútbol-hablan sobre fútbol; viven de sus padres- *viven sobre sus padres).

\section{ANÁLISIS DEL CORPUS}

En lo que sigue, procederemos -como ya hemos anunciado líneas más arriba- a someter a nuestro corpus a un análisis taxonómico a fin de corroborar cuales son las más productivas y, por tanto, los patrones más útiles para la creación de nuevas locuciones adverbiales.

A continuación exponemos las unidades que forman nuestro corpus. En total, 147 locuciones adverbiales iniciadas con la preposición de: 
LOPEZ, J. M.; JøRGEnSEn, A. La Preposición DE Como Inicio de Locución...

I Frecuencia de la estructura morfosintáctica de las locuciones adverbiales

\begin{tabular}{|c|c|c|c|c|c|c|}
\hline $\begin{array}{l}\text { LOCUCION } \\
\text { ADVERBIAL }\end{array}$ & $\begin{array}{l}\text { ESTRUCTURA } \\
\text { MORFOSINTÁCTICA }\end{array}$ & $\begin{array}{r}\mathbf{S . X X} \\
\text { oral }\end{array}$ & $\begin{array}{l}\text { s. XX } \\
\text { literat }\end{array}$ & $\begin{array}{l}\text { s. } \mathbf{X X} \\
\text { perod. }\end{array}$ & Total & $\%$ \\
\hline $\begin{array}{l}\text { De aquí en } \\
\text { adelante }\end{array}$ & $\begin{array}{l}\text { "de" + N./Adj./Adv. + prep. "en" } \\
+ \text { N./Adj./Adv. }\end{array}$ & 9 & 12 & 3 & 24 & $0.19 \%$ \\
\hline De aupa & $\begin{array}{l}\text { "de" }+ \text { [Art. }]+ \text { Palabra } \\
\text { idiomática }\end{array}$ & 2 & 3 & & 5 & $0.04 \%$ \\
\hline De baja & "de" + Adj. & 72 & 34 & 129 & 235 & $1.84 \%$ \\
\hline De balde & $\begin{array}{l}\text { "de" }+ \text { [Art.] + Palabra } \\
\text { idiomática }\end{array}$ & 1 & 70 & & 71 & $0.55 \%$ \\
\hline De bigotes & "de" + N & 2 & 14 & & 16 & $0.12 \%$ \\
\hline De bocado & "de" + N & 1 & & & 1 & $0.01 \%$ \\
\hline De boquilla & "de" + N & 5 & 1 & 1 & 7 & $0.05 \%$ \\
\hline De broma & "de" + N & 16 & 12 & 1 & 29 & $0.23 \%$ \\
\hline De bruces & $\begin{array}{l}\text { "de" }+[\text { Art. }]+\text { Palabra } \\
\text { idiomática }\end{array}$ & 7 & 61 & 3 & 71 & $0.55 \%$ \\
\hline De buen año & "de" + Ady. + N & & & & & \\
\hline De buenas & "de" + Adj. & 26 & 37 & 12 & 75 & $0.58 \%$ \\
\hline $\begin{array}{l}\text { De buenas a } \\
\text { primeras }\end{array}$ & $\begin{array}{l}\text { "de" + N./Adj./Adv. + prep. "a" } \\
+ \text { N./Adj./Adv. }\end{array}$ & 8 & 18 & 1 & 27 & $0.21 \%$ \\
\hline De buen grado & "de" + Ady. + N & 1 & 9 & 6 & 16 & $0.12 \%$ \\
\hline De buen humor & "de" + Ady. + N & 3 & 34 & & 37 & $0.29 \%$ \\
\hline De buen ver & "de" + Ady. + N & & 4 & 1 & 5 & $0.04 \%$ \\
\hline De buten & $\begin{array}{l}\text { "de" }+ \text { [Art. }]+ \text { Palabra } \\
\text { idiomática }\end{array}$ & & & & & \\
\hline De cabeza & "de" + N & 77 & 213 & 69 & 359 & $2.81 \%$ \\
\hline De cabo a rabo & $\begin{array}{l}\text { "de" + N./Adj./Adv. + prep. "a" } \\
+ \text { N./Adj./Adv. }\end{array}$ & 2 & 5 & 4 & 11 & $0.08 \%$ \\
\hline De carambola & "de" + N & & & 1 & 1 & $0.01 \%$ \\
\hline De carretilla & "de" + N & & & 1 & 1 & $0.01 \%$ \\
\hline De cesta & "de" + N & & & & & \\
\hline De churro & "de" + N & & 1 & & 1 & $0.01 \%$ \\
\hline De cine & "de" + N & 79 & 61 & 128 & 268 & $2.09 \%$ \\
\hline De cojones & "de" + N & & 1 & 1 & 2 & $0.02 \%$ \\
\hline
\end{tabular}


LOPEZ, J. M.; JøRGENSEN, A. LA Preposición DE Como Inicio de Locución...

\begin{tabular}{|c|c|c|c|c|c|c|}
\hline De color rosa & "de" + N + Ady. & 4 & 5 & 3 & 12 & $0.09 \%$ \\
\hline De corrida & "de" + N & & & 1 & 1 & $0.01 \%$ \\
\hline De corrido & "de" + Adj. & 5 & 10 & 1 & 16 & $0.12 \%$ \\
\hline De coña & $\begin{array}{l}\text { "de" }+ \text { [Art.] }+ \text { Palabra } \\
\text { idiomática }\end{array}$ & 3 & & & 3 & $0.02 \%$ \\
\hline De costado & "de" + N & 15 & 49 & 4 & 68 & $0.53 \%$ \\
\hline $\begin{array}{l}\text { De cuerpo } \\
\text { presente }\end{array}$ & "de" + N + Ady. & 3 & 11 & 4 & 18 & $0.14 \%$ \\
\hline De cuidado & "de" + N & 12 & 11 & 7 & 30 & $0.23 \%$ \\
\hline De culo & "de" + N & 5 & 8 & & 13 & $0.10 \%$ \\
\hline De día & "de" + N & 96 & 130 & 25 & 251 & $1.96 \%$ \\
\hline De día en día & $\begin{array}{l}\text { "de" + N./Adj./Adv. + prep. "en" } \\
+ \text { N./Adj./Adv. }\end{array}$ & 2 & 1 & 1 & 4 & $0.03 \%$ \\
\hline $\begin{array}{l}\text { De dientes } \\
\text { afuera }\end{array}$ & "de" + N + Ady. & & & & & \\
\hline De ensueño & "de" + N & 6 & 33 & 10 & 49 & $0.38 \%$ \\
\hline De entrada & "de" + N & 127 & 140 & 99 & 366 & $2.86 \%$ \\
\hline De espaldas & "de" + N & 75 & 164 & 24 & 263 & $2.05 \%$ \\
\hline De espanto & "de" + N & 17 & 75 & 1 & 93 & $0.72 \%$ \\
\hline De extranjis & $\begin{array}{l}\text { "de" }+ \text { [Art.] }+ \text { Palabra } \\
\text { idiomática }\end{array}$ & & & & & \\
\hline De fábula & "de" + N & 1 & 3 & & 4 & $0.03 \%$ \\
\hline De facto & $\begin{array}{l}\text { "de" }+ \text { [Art.] }+ \text { Palabra } \\
\text { idiomática }\end{array}$ & 19 & 1 & 19 & 39 & $0.30 \%$ \\
\hline De fantasía & "de" + N & 13 & 47 & 12 & 72 & $0.56 \%$ \\
\hline De fijo & "de" + Adj. & 1 & 6 & & 7 & $0.05 \%$ \\
\hline De flete & "de" + N & & & 6 & 6 & $0.05 \%$ \\
\hline De frente & "de" + N & 69 & 171 & 37 & 276 & $2.16 \%$ \\
\hline De gañote & $\begin{array}{l}\text { "de" }+[\text { Art. }]+\text { Palabra } \\
\text { idiomática }\end{array}$ & & & & & \\
\hline $\begin{array}{l}\text { De golpe y } \\
\text { porrazo }\end{array}$ & "de + N + Conj. "y" + N & 4 & 10 & 1 & 15 & $0.12 \%$ \\
\hline De gorra & "de" + N & & 3 & 1 & 4 & $0.03 \%$ \\
\hline
\end{tabular}


LOPEZ, J. M.; JøRGENSEN, A. LA Preposición DE Como Inicio de Locución...

\begin{tabular}{|c|c|c|c|c|c|c|}
\hline $\begin{array}{l}\text { De higos a } \\
\text { brevas }\end{array}$ & $\begin{array}{l}\text { "de" + N./Adj./Adv. + prep. "a" } \\
+ \text { N./Adj./Adv. }\end{array}$ & & & & & \\
\hline De hinojos & $\begin{array}{l}\text { "de" }+ \text { [Art. }]+ \text { Palabra } \\
\text { idiomática }\end{array}$ & 2 & 23 & & 25 & $0.19 \%$ \\
\hline De hito en hito & $\begin{array}{l}\text { "de" + N./Adj./Adv. + prep. "en" } \\
\text { + N./Adj./Adv. }\end{array}$ & 2 & 5 & 1 & 8 & $0.16 \%$ \\
\hline De hoz y coz & "de + N + Conj. "y" + N & 1 & & & 1 & $0.01 \%$ \\
\hline De huevos & "de" + N & & & & & \\
\hline De igual a igual & $\begin{array}{l}\text { "de" + N./Adj./Adv. + prep. "a" } \\
+ \text { N./Adj./Adv. }\end{array}$ & 5 & 10 & 3 & 18 & $0.14 \%$ \\
\hline De inmediato & "de" + Adj. & 143 & 354 & 146 & 643 & $5.03 \%$ \\
\hline $\begin{array}{l}\text { De la cabeza a } \\
\text { los pies }\end{array}$ & $\begin{array}{l}\text { "de" + N./Adj./Adv. + prep. "a" } \\
+ \text { N./Adj./Adv. }\end{array}$ & 3 & 12 & 2 & 17 & $0.13 \%$ \\
\hline De lance & "de" + N & & 1 & 1 & 2 & $0.02 \%$ \\
\hline $\begin{array}{l}\text { De la noche a la } \\
\text { mañana }\end{array}$ & $\begin{array}{l}\text { "de" + N./Adj./Adv. + prep. "a" } \\
\text { + N./Adj./Adv. }\end{array}$ & 35 & 32 & 21 & 88 & $0.69 \%$ \\
\hline De la leche & "de" + Art. + N & 15 & 11 & 32 & 58 & $0.45 \%$ \\
\hline Del carajo & $\begin{array}{l}\text { "de" }+[\text { Art. }]+\text { Palabra } \\
\text { idiomática }\end{array}$ & & 5 & 2 & 7 & $0.05 \%$ \\
\hline De lleno & "de" + Adj. & 39 & 44 & 33 & 116 & $0.90 \%$ \\
\hline De lo lindo & "de" + Art. + Adj. & 2 & 23 & 1 & 26 & $0.20 \%$ \\
\hline De los huevos & "de" + art. + N & & & & & \\
\hline De mala fe & "de" + Ady. + N & 2 & 7 & & 9 & $0.07 \%$ \\
\hline De mala hostia & "de" + Ady. + N & & & & & \\
\hline De mala leche & "de" + Ady. + N & & & & & \\
\hline De mala manera & "de" + Ady. + N & 10 & 16 & 3 & 29 & $0.23 \%$ \\
\hline De mal en peor & $\begin{array}{l}\text { "de" + N./Adj./Adv. + prep. "en" } \\
\text { + N./Adj./Adv. }\end{array}$ & 4 & 14 & & 18 & $0.14 \%$ \\
\hline De mal humor & "de" + Ady. + N & 16 & 35 & 4 & 55 & $0.43 \%$ \\
\hline De manga & "de" + N & 1 & 10 & 12 & 23 & $0.18 \%$ \\
\hline De mañana & "de" + N & 160 & 110 & 29 & 299 & $2.34 \%$ \\
\hline $\begin{array}{l}\text { De } \\
\text { mentirijilla(s) }\end{array}$ & "de" + N & 2 & 1 & & 3 & $0.02 \%$ \\
\hline
\end{tabular}


LOPEZ, J. M.; JøRGENSEN, A. LA Preposición DE Como Inicio de Locución...

\begin{tabular}{|c|c|c|c|c|c|c|}
\hline De miedo & "de" + N & 81 & 185 & 9 & 275 & $2.15 \%$ \\
\hline De mierda & "de" + N & 68 & 116 & 2 & 186 & $1.45 \%$ \\
\hline De milagro & "de" + N & 11 & 21 & 2 & 34 & $0.27 \%$ \\
\hline De mil diablos & "de" + N + Ady. & 2 & 2 & & 4 & $0.03 \%$ \\
\hline De momento & "de" + N & 214 & 50 & 63 & 327 & $2.56 \%$ \\
\hline De monos & "de" + N & 7 & 9 & 11 & 27 & $0.21 \%$ \\
\hline De narices & "de" + N & 4 & 12 & 3 & 19 & $0.15 \%$ \\
\hline $\begin{array}{l}\text { De ninguna } \\
\text { forma }\end{array}$ & "de" + Ady. + N & 11 & 2 & 6 & 19 & $0.15 \%$ \\
\hline $\begin{array}{l}\text { De ninguna } \\
\text { manera }\end{array}$ & "de" + Ady. + N & 257 & 102 & 30 & 389 & $3.89 \%$ \\
\hline De noche & "de" + N & 252 & 529 & 62 & 843 & $6.59 \%$ \\
\hline De nuevas & "de" + Adj. & 48 & 24 & 217 & 289 & $2.26 \%$ \\
\hline De oca en oca & $\begin{array}{l}\text { "de" + N./Adj./Adv. + prep. "en" } \\
+ \text { N./Adj./Adv. }\end{array}$ & & & & & \\
\hline De órdago & "de" + N & 2 & 3 & 1 & 6 & $0.05 \%$ \\
\hline De ordinario & "de" + Adj. & 10 & 29 & 3 & 42 & $0.33 \%$ \\
\hline De panza & "de" + N & 1 & 10 & & 11 & $0.09 \%$ \\
\hline De par en par & $\begin{array}{l}\text { "de" + N./Adj./Adv. + prep. "en" } \\
+ \text { N./Adj./Adv. }\end{array}$ & 15 & 70 & 6 & 91 & $0.71 \%$ \\
\hline De parte a parte & $\begin{array}{l}\text { "de" + N./Adj./Adv. + prep. "a" } \\
+ \text { N./Adj./Adv. }\end{array}$ & & 4 & & 4 & $0.03 \%$ \\
\hline De paso & "de" + N & 86 & 308 & 84 & 478 & $3.74 \%$ \\
\hline De pe a pa & $\begin{array}{l}\text { "de" + N./Adj./Adv. + prep. "a" } \\
+ \text { N./Adj./Adv. }\end{array}$ & 1 & 3 & & 4 & $0.03 \%$ \\
\hline De película & "de" + N & 18 & 28 & 48 & 94 & $0.73 \%$ \\
\hline De pelotas & "de" + N & & 3 & 4 & 7 & $0.05 \%$ \\
\hline De perilla & "de" + N & 2 & 1 & & 3 & $0.02 \%$ \\
\hline De pie & "de" + N & 172 & 674 & 63 & 902 & $7.05 \%$ \\
\hline De pistón & "de" + N & & 1 & 6 & 7 & $0.05 \%$ \\
\hline De plano & "de" + N & 32 & 31 & 22 & 85 & $0.66 \%$ \\
\hline De por medio & "de" + Prep. "por" + N & 37 & 61 & 22 & 120 & $0.94 \%$ \\
\hline De por vida & "de" + Prep. "por" + N & 3 & 17 & 15 & 35 & $0.27 \%$ \\
\hline
\end{tabular}


LOPEZ, J. M.; JøRGENSEN, A. LA Preposición DE Como Inicio de Locución...

\begin{tabular}{|c|c|c|c|c|c|c|}
\hline De prestado & "de" + Adj. & 1 & 3 & 3 & 7 & $0.05 \%$ \\
\hline De primera fila & "de" + Ady. + N & 1 & 3 & 11 & 15 & $0.12 \%$ \\
\hline De prisa & "de" + N & 10 & 88 & 6 & 104 & $0.81 \%$ \\
\hline De pronto & "de" + Adv. & 323 & 1549 & 87 & 1959 & $\%$ \\
\hline De propio & "de" + Adj. & & & & & \\
\hline De punta a cab $\phi$ & $\begin{array}{l}\text { "de" + N./Adj./Adv. + prep. "a" } \\
+ \text { N./Adj./Adv. }\end{array}$ & & & & & \\
\hline De punta a punt & $\begin{array}{l}\text { "de" + N./Adj./Adv. + prep. "a" } \\
+ \text { N./Adj./Adv. }\end{array}$ & 7 & 20 & 4 & 31 & $0.24 \%$ \\
\hline De puntillas & "de" + N & 5 & 28 & 2 & 35 & $0.27 \%$ \\
\hline De puta madre & "de" + N + Ady. & 25 & 2 & & 27 & $0.21 \%$ \\
\hline De raíz & "de" + N & 10 & 24 & 18 & 52 & $0.41 \%$ \\
\hline De rebote & "de" + N & 3 & 4 & 2 & 9 & $0.07 \%$ \\
\hline De rechazo & "de" + N & 16 & 28 & 30 & 74 & $0.59 \%$ \\
\hline De rondón & $\begin{array}{l}\text { "de" }+[\text { Art. }]+\text { Palabra } \\
\text { idiomática }\end{array}$ & 1 & 2 & 1 & 4 & $0.03 \%$ \\
\hline De seguido & "de" + N & & 7 & & 7 & $0.05 \%$ \\
\hline De seguro & "de" + N & 17 & 82 & 19 & 118 & $0.92 \%$ \\
\hline De sopetón & $\begin{array}{l}\text { "de" }+[\text { Art. }]+\text { Palabra } \\
\text { idiomática }\end{array}$ & 1 & 19 & 1 & 21 & $0.16 \%$ \\
\hline De sobra & "de" + N & 40 & 84 & 22 & 146 & $0.14 \%$ \\
\hline De soslayo & "de" + N & 3 & 38 & 3 & 44 & $0.34 \%$ \\
\hline De súbito & $\begin{array}{l}\text { "de" }+[\text { Art. }]+ \\
\text { idiomática }\end{array}$ & 40 & 84 & 22 & 146 & $1.14 \%$ \\
\hline De tanto en tanto & $\begin{array}{l}\text { "de" + N./Adj./Adv. + prep. "en" } \\
+ \text { N./Adj./Adv. }\end{array}$ & 6 & 152 & 2 & 160 & $1.25 \%$ \\
\hline De tapadillo & $\begin{array}{l}\text { "de" }+ \text { [Art.] }+ \text { Palabra } \\
\text { idiomática }\end{array}$ & & & 1 & 1 & $0.01 \%$ \\
\hline De tarde & "de" + N & 12 & 64 & 7 & 83 & $0.65 \%$ \\
\hline De tarde en tarde & $\begin{array}{l}\text { "de" + N./Adj./Adv. + prep. "en" } \\
+ \text { N./Adj./Adv. }\end{array}$ & 5 & 24 & 1 & 30 & $0.23 \%$ \\
\hline De tejas abajo & "de" + N + Ady. & & & & & \\
\hline
\end{tabular}


LOPEZ, J. M.; JøRGENSEN, A. LA Preposición DE Como Inicio de Locución...

\begin{tabular}{|c|c|c|c|c|c|c|}
\hline De tejas arriba & "de" + N + Ady. & & & & & \\
\hline $\begin{array}{l}\text { De tiempo en } \\
\text { tiempo }\end{array}$ & $\begin{array}{l}\text { "de" + N./Adj./Adv. + prep. "en" } \\
+ \text { N./Adj./Adv. }\end{array}$ & 5 & 11 & 2 & 18 & $0.14 \%$ \\
\hline De todas formas & "de" + Ady. + N & 185 & 42 & 32 & 259 & $2.02 \%$ \\
\hline De todos modos & "de" + Ady. + N & 142 & 276 & 52 & 470 & $3.67 \%$ \\
\hline De tope a tope & $\begin{array}{l}\text { "de" + N./Adj./Adv. + prep. "a" } \\
+ \text { N./Adj./Adv. }\end{array}$ & & & & & \\
\hline $\begin{array}{l}\text { De trecho en } \\
\text { trecho }\end{array}$ & $\begin{array}{l}\text { "de" + N./Adj./Adv. + prep. "en" } \\
+ \text { N./Adj./Adv. }\end{array}$ & 2 & 18 & & 20 & $0.16 \%$ \\
\hline De una sentada & "de" + art. + N & & 2 & & 2 & $0.02 \%$ \\
\hline De una tirada & "de" + art. + N & & & 6 & 6 & $0.05 \%$ \\
\hline $\begin{array}{l}\text { De un momento } \\
\text { a otro }\end{array}$ & $\begin{array}{l}\text { "de" + N./Adj./Adv. + prep. "a" } \\
+ \text { N./Adj./Adv. }\end{array}$ & & & & & \\
\hline De un plomazo & "de" + Art. + N & & & & & \\
\hline De un plumazo & "de" + Art. + N & 8 & 3 & 2 & 13 & $0.10 \%$ \\
\hline De un voleo & "de" + Art. + N & & & & & \\
\hline De vértigo & "de" + N & 3 & 16 & 6 & 25 & $0.20 \%$ \\
\hline $\begin{array}{l}\text { De vez en } \\
\text { cuando }\end{array}$ & $\begin{array}{l}\text { "de" + N./Adj./Adv. + prep. "en" } \\
+ \text { N./Adj./Adv. }\end{array}$ & 203 & 302 & 35 & 540 & $4.22 \%$ \\
\hline De vicio & "de" + N & 7 & 9 & & 16 & $0.12 \%$ \\
\hline
\end{tabular}

A continuación se expone una sinopsis de los patrones estructurales sobre los que se monta todo el corpus, junto a la cantidad de expresiones que responden a cada patrón. Para terminar se añade el porcentaje de uso que representa cada patrón sintáctico. 
LOPEZ, J. M.; JØRGENSEN, A. LA Preposición DE Como Inicio de Locución...

\section{Frecuencia de los diferentes patrones sintácticos}

\begin{tabular}{|c|c|c|c|c|}
\hline $\begin{array}{c}\text { Estructura } \\
\text { morfosintáctica }\end{array}$ & Cantidad & $\%$ & $\begin{array}{l}\text { Frecuencia } \\
\text { de uso }\end{array}$ & $\%$ \\
\hline Prep. "de" + N & 62 & $42.17 \%$ & 6.623 & $53.00 \%$ \\
\hline Prep. "de" + Art. + N & 8 & $5.44 \%$ & 116 & $0.91 \%$ \\
\hline Prep. "de" + N + Ady. & 7 & $4.76 \%$ & 61 & $0.48 \%$ \\
\hline Prep. "de" + Ady. + N & 14 & $9.52 \%$ & 1.393 & $12.19 \%$ \\
\hline Prep. "de" + Adj. & 11 & $7.48 \%$ & 787 & $6.15 \%$ \\
\hline Prep. "de" + Art. + Adj. & 1 & $0.68 \%$ & 26 & $0.20 \%$ \\
\hline Prep. "de" + Adv. & 2 & $2.04 \%$ & 1.959 & $15.31 \%$ \\
\hline $\begin{array}{l}\text { Prep. "de" + } \\
\text { N./Adj./Adv. + Prep. "a" } \\
+ \text { N./Adj./Adv. }\end{array}$ & 12 & $8.16 \%$ & 179 & $1.40 \%$ \\
\hline $\begin{array}{l}\text { Prep. "de" + } \\
\text { N./Adj./Adv. + Prep. } \\
\text { "en" + N./Adj./Adv. }\end{array}$ & 11 & $7.48 \%$ & 913 & $7.14 \%$ \\
\hline $\begin{array}{l}\text { Prep. "de" + [Art.] + } \\
\text { Palabra idiomática }\end{array}$ & 14 & $9.52 \%$ & 393 & $3.07 \%$ \\
\hline $\begin{array}{l}\text { Prep. "de + N + Conj. "y" } \\
+\mathrm{N}\end{array}$ & 2 & $1.36 \%$ & 16 & $0.12 \%$ \\
\hline $\begin{array}{l}\text { Prep. "de" + Prep. "por" } \\
+\mathrm{N}\end{array}$ & 2 & $1.36 \%$ & 155 & $1.21 \%$ \\
\hline
\end{tabular}

\section{CONCLUSIONES}

De los resultados mostrados en los cuadros I y II se pueden sacar las siguientes conclusiones. En primer lugar, poca duda cabe de que los patrones morfosintácticos más productivos en nuestro esquema son los de estructura más reducida, es decir, los que presentan una menor complejidad. Algo más de un $53 \%$ del corpus se monta sobre el patrón reducido Prep. "de" + [art.] + N.: de la leche, de pie, de monos. También muestran una relativa alta frecuencia los patrones de sustantivo con adyacencia (14\%), ya sea esta adjetiva o preposicional. En este sentido puede decirse que los hablantes tienden a recrear, preferiblemente, estructuras pluriverbales de 
LOPEZ, J. M.; JøRGENSEN, A. LA Preposición DE CoMo INICIO de Locución...

gran simplicidad para generar nuevos adverbios.

Es también digno de reseña la alta productividad del patrón con palabra idiomática (10\%), si bien, a la vez llama la atención la baja frecuencia de uso de dichas locuciones ( $3 \%$ ). Dicho término -palabra idiomática- fue definido por Zuluaga (1980, p. 102) como "unidades léxicas formadas por un elemento lingüístico que, por diversas razones, aparece exclusivamente dentro del marco de una locución y que, por tanto, funciona como signo diacrítico".

Otro aspecto que cabe destacar es la alta productividad de patrones sintácticos de mayor complejidad como son los representados por Prep. "de" + N./Adj./Adv. + Prep. "a" + N./Adj./Adv. (8.16\%) y Prep. "de" + N./Adj./ Adv. + Prep. "en" $+N . / A d j . / A d v .(7.48 \%)$, si bien la frecuencia de uso no es proporcional en el primero de los casos, al representar solo un $3 \%$ del corpus. Ello parece indicar que, pese a que el patrón se recrea, los hablantes se resisten a utilizar con frecuencia dichos adverbios.

En cierta medida ello parece contradecir algunas de las reglas de la comunicación en que se basa la moderna pragmática como la economía en el lenguaje (HOCKETT, 1975) o la "máxima de manera" establecida por Grice, una de cuyas exigencias es la brevedad en el mensaje (Cf. ESCANDELL, 1993).

Como resumen de lo observado puede decirse que, en líneas generales, los adverbios de carácter pluriverbal están fuertemente representados cuando se sustentan en estructuras sintácticas elementales, mientras su uso disminuye casi de modo inversamente proporcional cuando aumenta la complejidad estructural. No obstante, cabe señalar algunas excepciones al respecto que, a nuestro juicio, podrían ser explicadas en base a dos parámetros: por un lado uno objetivo que tendría que ver con el número de elementos sustitutivos potenciales de carácter monoverbal de dicha locución, y un segundo, éste de carácter subjetivo, que estaría mas relacionado con las modas o la popularización de una locución en una zona o momento determinado.

\section{RESUMO}

O presente trabalho tem por objetivo analisar a estrutura morfosintática das locuções adverbiais, mais concretamente daquelas iniciadas com a preposição de. Para tanto, a totalidade das citadas formações pluriverbais foi extraída de dois 
LOPEZ, J. M.; JØRGENSEN, A. LA Preposición DE Como Inicio de Locución...

dicionários: um relacionado à língua espanhola geral, o $D R A E$, e outro de caráter fraseológico, o Diccionario de Locuciones y Expresiones Familiares. Depois de obtidas todas as estruturas, foram estabelecidos padrões funcionais, o que nos permitiu observar quais são as estruturas produtivas, e, portanto, servem de base para novas criações, e quais representam padrões pouco eficazes para sua reprodução no processo de criação de novas unidades.

Palavras-chave: Padrões; Estrutura Morfosintática; Locução Adverbial; Índice de Frequência.

\section{ABSTRACT}

This paper focuses on the morfosyntactic structure of the adverbial expressions, more spesificly on those that begin with the preposition $d e$. The material is taken from two dictionaries: one general dictionary, the $D R A E$ and another phraseological one, the Diccionario de Locuciones y Expresiones Familiares. Having identified all the relevant structures, we continued establishing a functional pattern, which has made it possible to observe which structures are the productive ones, that can be used as a base for new examples, and which are less efficient patterns when when it comes to reproduction and the creation of new units.

Keywords: Patterns; Morfosyntactic Structure; Adverbial Expression; Frequency.

\section{REFERENCIAS}

BUITRAGO, Alberto. Diccionario de dichos y frases hechas. Madrid: Espasa, 2002. 1038 p. CASARES, Julio. Introducción a la lexicografía moderna. Madrid: CSIC, 1992 [1950]. 354 p.

CASTILLO CARBALLO, María Auxiliadora. Lingüística de corpus y fraseología: algunas consideraciones sobre las locuciones verbales. In: CORPAS PASTOR, Gloria (Ed.). Lenguas de Europa: estudios de fraseología, fraseografía y traducción. Granada: Comares, 2000. p. 95-125.

CORPAS PASTOR, Gloria. Manual de fraseología española. Madrid: Gredos, 1996. 337 p.

COSERIU, Eugenio. Principios de semántica estructural. Madrid: Gredos, 1986 [1977]. p. 246.

DANTE HERNÁNDEZ, Ana. iEs pan comido!: [Expresiones fijas clasificadas en funciones comunicativas]. Madrid: Edinumen, 2003. 117 p.

ESCANDELL, María Victoria. Introducción a la pragmática. Barcelona: Anthropos. 1993. $220 \mathrm{p}$. 
LOPEZ, J. M.; JøRGEnSEn, A. La Preposición DE Como Inicio de Locución...

GARCÍA-PAGE, Mario. Sobre implicaciones lingüísticas. Solidaridad léxica y expresión fija. Estudios Humanísticos. Filología, León, v.12, p. 215-227, 1990.

GRICE, Herbert. Logic and conversation. In: COLE, P.; MORGAN, J. (Eds.). Syntax and semantics, v. 3. New York: Academic Press, 1975. p. 43-58

HALLIDAY, Michael A. Linguistic Studies of Text and Discourse. London/New York: Continuum, 2002, $301 \mathrm{p}$.

HOCKETT, Charles. Curso de lingüística moderna. Buenos Aires: Eudeba, 1979. 287p.

LÓPEZ, María L. Problemas y métodos en el análisis de las preposiciones. Madrid: Gredos, 1982, $223 \mathrm{p}$.

MARTÍNEZ LÓPEZ, Juan A.; JORGENSEN, Annette M. Diccionario de locuciones y expresiones familiares. Madrid: Ediciones de la Torre, 2007, 510 p.

MARTÍNEZ MARÍN, Juan. Las expresiones fijas en español: perspectivas teoricodescriptiva y aplicada. Gramma-Temas, León, v. 1. p. 181-196, 1992.

MOLINER, María. Diccionario de uso del español. Madrid: Gredos. 1992. 3031 p.

POTTIER, Bernard. Lingüística general. Teoría y descripción. Madrid: Gredos, 1977. 425p.

REAL ACADEMIA ESPAÑola. Diccionario de la lengua española. Madrid: Espasa Calpe. 1992. $2133 \mathrm{p}$.

RUIZ GURILLO, Leonor. La fraseología del español coloquial. Barcelona: Ariel. 1998. 128 p.

SECO, Manuel et al. Diccionario fraseológico documentado del español actual, Madrid: Aguilar. 2004. 1084 p.

TRISTÁ PÉREZ, Antonia. Fraseología y contexto. La Habana: Ciencias Sociales, 1980.195 p.

VAN DIJK, Teun A. Texto y contexto. Madrid: Cátedra. 1993. 357 p.

ZULUAGA, Alberto. Introducción al estudio de las expresiones fijas. Frankfurt a Main: Peter D. lang, 1980.247 p.

Submetido em: 28/08/2007.

Aceito em: 16/09/2008. 